\title{
Environmentally friendly analysis of emerging contaminants by pressurized hot water extraction-stir bar sorptive extraction-derivatization and gas chromatography-mass spectrometry
}

\author{
Marina G. Pintado-Herrera • Eduardo González-Mazo • \\ Pablo A. Lara-Martín
}

Received: 15 August 2012 /Revised: 18 September 2012 / Accepted: 21 September 2012 / Published online: 11 October 2012

(C) Springer-Verlag Berlin Heidelberg 2012

\begin{abstract}
This work describes the development, optimization, and validation of a new method for the simultaneous determination of a wide range of pharmaceuticals (betablockers, lipid regulators...) and personal care products (fragrances, UV filters, phthalates...) in both aqueous and solid environmental matrices. Target compounds were extracted from sediments using pressurized hot water extraction followed by stir bar sorptive extraction. The first stage was performed at 1,500 psi during three static extraction cycles of $5 \mathrm{~min}$ each after optimizing the extraction temperature $\left(50-150{ }^{\circ} \mathrm{C}\right)$ and addition of organic modifiers ( $\%$ methanol) to water, the extraction solvent. Next, aqueous extracts and water samples were processed using polydimethylsiloxane bars. Several parameters were optimized for this technique, including extraction and desorption time, ionic strength, presence of organic modifiers, and $\mathrm{pH}$. Finally, analytes were extracted from the bars by ultrasonic irradiation using a reduced amount of solvent $(0.2 \mathrm{~mL})$ prior to derivatization and gas chromatography-mass spectrometry analysis. The optimized protocol uses minimal amounts of organic solvents $(<10 \mathrm{~mL} /$ sample $)$ and time $(\approx 8 \mathrm{~h} / \mathrm{sam}$ ple) compared to previous existing methodologies. Low standard deviation (usually below $10 \%$ ) and limits of detection (sub-ppb) vouch for the applicability of the methodology for the analysis of target compounds at trace levels. Once developed, the method was applied to determine
\end{abstract}

M. G. Pintado-Herrera • E. González-Mazo •

P. A. Lara-Martín ( $\square)$

Departamento de Química Física, Facultad de Ciencias

del Mar y Ambientales, Universidad de Cádiz - Campus de

Excelencia Internacional del Mar (CEI-MAR),

Campus Río San Pedro s/n,

11510 Puerto Real, Cádiz, Spain

e-mail: pablo.lara@uca.es concentrations of these compounds in several types of sample (wastewater, seawater, pore water, and sediment) from Cadiz Bay (SW Spain). To our knowledge, these findings represent the first information available on the presence of some of the target compounds in the marine environment.

Keywords Pharmaceuticals · Personal care products · Pressurized hot water extraction (PHWE) - Stir bar sorptive extraction (SBSE) · Gas chromatography-mass spectrometry (GC-MS)

\section{Introduction}

'Emerging organic contaminants' (EOCs) covers a large group of substances, whose presence in the environment is not necessarily new, but which are not included in routine monitoring programs. Some of these chemicals may be candidates for future regulation, depending on present and future research on their toxicity, potential health effects and public perception, and on monitoring data obtained regarding their occurrence in different environmental compartments (through the European Union Norman Project) [1]. EOCs are widely used in consumer goods, such as fragrances, antiseptics, and drugs for human and veterinary application. Pharmaceuticals and personal care products (PPCPs) comprise an interesting group of EOCs that are being continuously released into the environment mainly through wastewater effluents, both treated and untreated $[2,3]$, or run-off from biosolids applied to land [4]. This group includes pharmaceutically active compounds such as analgesics, antiinflammatories, psychiatric drugs, lipid regulators, antibiotics, antiseptics, anticonvulsants..., and personal care products 
such as fragrances, plasticizers, UV filters, and insect repellents.... Concentrations of these substances in aqueous samples have been measured within a range from less than $10 \mathrm{ng} / \mathrm{L}$ (in river water) to more than $100 \mu \mathrm{g} / \mathrm{L}$ (in raw wastewater) [5]. Although less frequently analyzed, PPCPs have been also detected in soil and sediment samples, at concentrations typically between 0.5 and $10 \mathrm{ng} / \mathrm{g}$ [6]. In spite of being present at very low concentrations, these chemicals may be harmful to wildlife, considering possible synergic effects when mixtures of several chemicals are present [7]. Additionally, PPCPs do not need to persist in the environment to cause negative effects, since they are being introduced continuously. There is therefore growing concern about their potential risk in soils and the receiving aquatic environment. As examples, bioaccumulation in fish has been measured for some hydrophobic PPCPs (UV filters, fragrances...) [8]; antibiotics can promote resistant bacteria populations [9]; and endocrine-disrupting compounds (EDCs) may cause hermaphroditism [10].

Method development is the necessary first stage in studying the occurrence, behavior, and fate of PPCPs in the environment. Due to their low levels, analytes in samples need to be extracted and concentrated prior to analysis. Most analytical protocols on the extraction of contaminants from aqueous samples (groundwater, surface water, and wastewater) rely on using liquid-liquid extraction (LLE) or solidphase extraction (SPE) [2]. As drawbacks, these techniques generally require large volumes of organic solvents, additional clean-up steps, and extensive sample manipulation. The use of sorptive techniques, such as solid-phase microextraction (SPME) [11] and stir bar sorptive extraction (SBSE) [12], has increased over the last decade. Their main advantages are solventless sample enrichment, minimal sample manipulation (therefore reducing the risk of contamination), reduction of sample preparation time, and re-use of the polymer fiber or bar after extraction. Here we have focused our attention on SBSE because a wide range of analytes can be extracted simultaneously and their sorption is enhanced compared to SPME. To date, several multiresidue methods have been described that employ SBSE to isolate different classes of compounds in environmental matrices; most of these methods are focused on persistent organic pollutants (POPs) such as pesticides, polycyclic aromatic hydrocarbons, and chlorinated compounds [13]. More recently, new methods for SBSE extraction and determination of PPCPs have been developed [3]. Once analytes have been extracted, desorption can be accomplished either thermally, thermal desorption (TD), which requires a TD unit usually coupled to gas chromatography-mass spectrometry (GC-MS), or by liquid desorption (LD) using a small volume $(<1 \mathrm{~mL})$ of organic solvent. $\mathrm{LD}$ is preferred over TD for those analytes that require a derivatization step prior to
GC-MS (such as many non-volatile pharmaceuticals), and/or prior to liquid chromatography-mass spectrometry analysis.

Extraction of PPCPs and many other organic contaminants from solid matrices (sludge, sediment, and soils) has been carried out widely using several techniques such as Soxhlet extraction [14], ultrasonic solvent extraction [15] and microwave-assisted solvent extraction [16]. Other extraction techniques, such as pressurized liquid extraction (PLE) are preferred due to its automation and rapidness, regarding to the abovementioned. We have researched a PLE modification known as pressurized hot water extraction (PHWE). Here, the use of organic solvents is minimized by replacing them with water as extraction solvent. Water, a highly polar solvent, can modify its properties under high temperatures and pressures [17]. Under these conditions, water viscosity and surface tension decreases and diffusivity increases, so it behaves like some organic solvents and can effectively extract a wide range of analytes with low to medium polarity. This technique has recently been applied to the extraction of POPs [18] and PPCPs [19] from sludge samples.

The aim of this research is to combine both extraction techniques (SBSE and PHWE), thus developing a costeffective, fast, simple, and environmentally friendly multiresidue methodology for the simultaneous extraction and determination of selected PPCPs in the environment. Target analytes include widely used pharmaceuticals (e.g., ibuprofen, naproxen, acetaminophen, gemfibrozil...) and personal care products (e.g., triclosan, octocrylene, bisphenol A, musk xylene...). Extraction and desorption of target compounds has been carried out by SBSE-LD for aqueous samples, and by PHWE-SBSE-LD for solid samples. The method has been also applied to the analysis of wastewater, seawater, pore water, and sediment samples from Cadiz Bay (SW Spain).

\section{Experimental}

Materials and reagents

Methanol, ethyl acetate, and acetonitrile were of chromatography quality, purchased from Scharlau (Barcelona, Spain). Sodium chloride was purchased from Merck and water was Milli-Q quality. Phosphoric acid and purified siliceous earth were purchased from Panreac (Barcelona, Spain). N-(tertbutyldimethylsilyl)- $N$-methyltrifluoroacetamide (MTBSTFA) and acetic anhydride from Sigma Aldrich (Madrid, Spain) were used as derivatization agents. Commercial polydimethylsiloxane (PDMS) stir bars $(10 \times 0.5 \mathrm{~mm}$, length $\times$ film thickness) and a 15 position magnetic stirrer were purchased from Gerstel (Mulheim a/d Ruhr, Germany). Glass microfiber 
filters $(0.45 \mu \mathrm{m}$ pore size $)$ were purchased from Pall Corporation (Michigan, United States).

\section{Chemicals}

$N, N$-diethyl-meta-toluamide (DEET), galaxolide (HHCB), musk xylene (MX), bisphenol A d14 (BpA-d14), triclosan d3 (TCS-d3), methyl-triclosan $13 \mathrm{C}_{12}$ (MTCS-13C 12 ), and 4$N$-nonylphenol d8 (NP-d8) were purchased from Dr Ehrenstorfer GmbH (Augsburg, Germany). Ibuprofen, ketoprofen, carbamazepine, diclofenac sodium, 2-hydroxy-4-methoxybenzophenone (BP-3), octocrylene (OC), nonylphenol technical mixture (NP), diethyl-phthalate (DEP), dibutylphthalate (DBP), bisphenol A (BpA), estrone (E1), naproxen, cyclopirox, triclosan (TCS), methyl triclosan (MTCS), 2-(p-chlorophenoxy)-2-methylpropionic acid (clofibric acid), metronidazole, mefenamic acid, acetaminophen, fenofibrate, gemfibrozil, allopurinol, fenoprofen calcium hydrate, amitriptyline, caffeine anhydrous, acetylsalicylic acid, atenolol, terbinafine hydrochloride, trimetropin, antipyrine crystalline, and octylphenol (OP) were purchased from Sigma-Aldrich (Madrid, Spain). Stock solutions of these analytes were prepared in methanol and stored at $-20{ }^{\circ} \mathrm{C}$ in amber vials.

\section{Sample collection}

Both aqueous and solid samples were collected in summer 2010 from the sewage-impacted salt marsh environment of the Bay of Cadiz (SW Spain), surrounded by several towns and cities comprising a total of 640,000 inhabitants. Wastewater samples were collected from the influent and effluent of a wastewater treatment plant (WWTP) at Puerto Real. This facility, equipped with biologic treatment, treats the sewage coming from this town (41,000 inhabitants), receiving an average flow of $8,000 \mathrm{~m}^{3} \mathrm{day}^{-1}$ and discharging into the Bay of Cadiz. Surface seawater samples were taken at Santa Maria Beach, an urban beach at Cadiz $(157,000$ inhabitants) (36 $\left.31^{\prime} 5.27^{\prime \prime} \mathrm{N} ; 6^{\circ} 17^{\prime} 15.10^{\prime \prime} \mathrm{W}\right)$. Water samples were collected in clean amber-glass bottles $(1 \mathrm{~L})$, filtered $(0.45 \mu \mathrm{m})$, and placed in a cooler at $4{ }^{\circ} \mathrm{C}$ prior to analysis, which was carried out within $24 \mathrm{~h}$. Sediment cores (50 cm length $\times 6 \mathrm{~cm}$ diameter) were taken in a tidal channel (Sancti Petri channel) in the south of the bay $\left(36^{\circ} 28^{\prime} 23^{\prime \prime} \mathrm{N}\right.$; $\left.6^{\circ} 10^{\prime} 50^{\prime \prime} \mathrm{W}\right)$. Cores were maintained in vertical position at $4{ }^{\circ} \mathrm{C}$ during their transport to the laboratory, where they were frozen at $-20{ }^{\circ} \mathrm{C}$. Later, frozen cores were sectioned into $2 \mathrm{~cm}$ layers (from surface to $28 \mathrm{~cm}$ depth) that were centrifuged at 4,500 rpm during $20 \mathrm{~min}$ to obtain pore water samples (placed in $20 \mathrm{~mL}$ amber-glass vials for later analysis). Sediments were freeze-dried and milled using a zirconium oxide ball mill before analysis. Selected depths were used in this work $(0,10$, and $20 \mathrm{~cm})$.
Extraction and analysis of target compounds

\section{Water samples}

Three $100-\mathrm{mL}$ aliquots of each wastewater and surface water sample $(10 \mathrm{~mL}$ for pore water, instead) were acidified with phosphoric acid to $\mathrm{pH} 2$ and placed in amber-glass flasks together with PDMS bars $(10 \mathrm{~mm}$ length $\times 0.5 \mathrm{~mm}$ thickness). Surrogates, MTCS- $13 \mathrm{C}_{12}$ and NP-d8, were added $(5 \mu \mathrm{g} / \mathrm{L})$ to determine possible fluctuations during the extraction procedure. Ten percent methanol was also added to the samples, which were stirred at $900 \mathrm{rpm}$ during $8 \mathrm{~h}$ at room temperature and in darkness conditions. After the extraction, stir bars were removed magnetically, dried with a tissue, and placed inside vials containing $200 \mu \mathrm{l}$ of ethyl acetate to carry out liquid desorption by sonication during $30 \mathrm{~min}$. Extraction efficiency was optimized by testing the influence of several parameters: ionic strength, desorption solvent, desorption time, $\mathrm{pH}$, volume of organic modifier, extraction time, and bar size. Recovery experiments (percent of standard added to sample recovered during extraction) were also carried out in triplicate by spiking aliquots of $10 \mathrm{~mL}$ of Milli-Q water with $10 \mu \mathrm{g} / \mathrm{L}$ of all target compounds.

\section{Solid samples}

Sediment samples were extracted in triplicate using an accelerated solvent extraction ASE 200 unit from Dionex. Briefly, $2 \mathrm{~g}$ of dried and milled sediment were mixed with $18 \mathrm{~g}$ of siliceous earth and placed into a steel extraction cell $(22 \mathrm{~mL}$ ). Surrogates, MTCS-13C 12 and NP-d8, were spiked at $50 \mu \mathrm{g} / \mathrm{kg}$ to account for losses during the extraction procedure. Extraction was performed with water containing $10 \%$ methanol as organic modifier (PHWE), at $100{ }^{\circ} \mathrm{C}$ and at a pressure of $1,500 \mathrm{psi}$, using three cycles of $5 \mathrm{~min}$ each (preheating time $6 \mathrm{~min}$, flush volume $60 \%$ and purge time $60 \mathrm{~s})$. Later, extracts were acidified with phosphoric acid (pH 2) before carrying out SBSE using the same conditions as for the aqueous samples. PHWE was optimized testing several percentages of organic modifiers in water, extraction temperatures, dispersants, and $\mathrm{pH}$ values. Extraction recovery percentages were calculated by spiking $2 \mathrm{~g}$ of nonpolluted sediments with $100 \mu \mathrm{g} / \mathrm{kg}$ of all target compounds, allowing $24 \mathrm{~h}$ before extraction at $4{ }^{\circ} \mathrm{C}$ to reach equilibrium. These spiked sediments were treated in the same way as the real samples, and analyzed in triplicate.

\section{GC-MS analysis}

A derivatization step was required after liquid desorption due to the presence of several non-volatile polar target analytes. MTBSTFA and acetic anhydride were tested as 
derivatization agents. Separation and detection of target compounds were performed using a 6,890 N Agilent GC system coupled to a 5,973 mass spectrometric detector (Agilent Technologies. Little Falls, DE, USA). Capillary gas chromatography analysis was carried out on a HP5MS column $(30 \mathrm{~m} \times 0.25 \mathrm{~mm}$ i.d. $\times 0.25 \mu \mathrm{m}$ film thickness of $5 \%$ phenyl, $95 \%$ polydimethylsiloxane), keeping the helium carrier gas flow at $1 \mathrm{mLmin}^{-1}$, the injection port temperature at $280{ }^{\circ} \mathrm{C}$, and injecting $1 \mu \mathrm{L}$ of sample in splitless mode. The column temperature ramp for an effective separation of analytes was as follows: $70^{\circ} \mathrm{C}$ for $1 \mathrm{~min}$, increased at $35^{\circ} \mathrm{Cmin}^{-1}$ to $180{ }^{\circ} \mathrm{C}$, then at $4.50{ }^{\circ} \mathrm{Cmin}^{-1}$ to $290{ }^{\circ} \mathrm{C}$, and held for $8 \mathrm{~min}$. The electron impact source, transfer line and quadrupole analyzer temperatures were 250, 280, and $150{ }^{\circ} \mathrm{C}$, respectively. The mass detector acquired in selected ion-monitoring (SIM) mode using $70 \mathrm{eV}$ as electron impact ionization (EI) energy. Identification and quantification of target compounds was based on comparing retention times and two different ions $(Q 1$ for quantification, $Q 2$ for confirmation) to those for commercially available pure standards. Calibration curves were constructed for each compound in the range of $0.01-$ $10 \mu \mathrm{g} / \mathrm{L}$ for aqueous samples, and between $1-100 \mu \mathrm{g} / \mathrm{kg}$ for solid samples. Internal standards, BpA-d14 and TCS-d3, were added to sample vials at $250 \mu \mathrm{g} / \mathrm{L}$ before injection to correct possible fluctuations in the MS signal. The reproducibility and repeatability of the method were also evaluated by performing three successive extractions and injections of the same sample and by re-analyzing same batch of standards 2 weeks after their first analysis. Limits of detection (LODs) were established for signal-to-noise ratio of 3 as the minimum detectable signal.

\section{Results and discussion}

\section{SBSE-LD optimization}

For the development of this method, and due to the large number and diversity of analytes considered, parameters affecting SBSE-LD efficiency were evaluated in order to optimize extraction conditions. These parameters were: PDMS bar size, sample volume, extraction time, amount of salt, $\mathrm{pH}$, amount of organic modifier ( $\%$ methanol added to the sample), desorption solvent, and desorption time. All the experiments were performed in triplicate and/or quintuplicate at room temperature $\left(20{ }^{\circ} \mathrm{C}\right)$ and in darkness conditions to avoid possible photodegradation of light-sensitive compounds such as triclosan.

\section{SBSE conditions}

SBSE extraction is an equilibrium process between an aqueous phase (the sample) and a solid phase (the PDMS coating of the stir bar) [20]. Therefore, the process is affected by the extraction time and the agitation speed of the PDMS bars. In this work, we decided to set the agitation speed at $900 \mathrm{rpm}$, in agreement with other authors $[13,21]$ and taking into account that, although higher speeds could accelerate the extraction process, this would also reduce the lifetime of the stir bar [22]. The optimum extraction time was determined by analyzing the concentration of target compounds on the stir bars at time intervals from $30 \mathrm{~min}$ to $24 \mathrm{~h}$. The extraction process is completed once equilibrium is reached between the analytes of the sample and those of the PDMS. The concentration in the stir bars for all extracted analytes increases as time passes (Fig. 1). Equilibrium conditions were reached after $7 \mathrm{~h}$, and no significant changes in the extraction efficiency could be observed after this. Therefore, PDMS bars could be removed from the sample at anytime between 7 and $24 \mathrm{~h}$ (end of the experiment) for a reliable analysis. An extraction period of $8 \mathrm{~h}$ is used for real samples as a good compromise between sensitivity and practicality.

Optimization of physicochemical properties of the aqueous matrix ( $\mathrm{pH}$, ionic strength, organic modifiers...) is also important for improving the extraction of organic compounds. First, the effect of acidifying the sample was studied at selected $\mathrm{pH}$ values $(2,4$, and 7$)$. Most target compounds were not affected by changes in the $\mathrm{pH}$ of the sample (depending on the analyte, extraction efficiencies may increase or decrease by only 10 to $20 \%$ ). However, significantly higher recoveries were obtained for some pharmaceuticals at lower $\mathrm{pH}$ values (Fig. 2a). This effect was observed for compounds showing $\mathrm{p} K_{\mathrm{a}}$ values lower than 7 (e.g., $\mathrm{p} K_{\mathrm{a}}$ values for diclofenac, mefenamic acid, or fenoprofen are 4.1, 4.2, and 4.5, respectively) [23]. The non-ionized form of these compounds prevails in acid aqueous solutions, so their interaction with the PDMS bar increases [3, 19]. Therefore, $\mathrm{pH} 2$ was selected for further experiments.

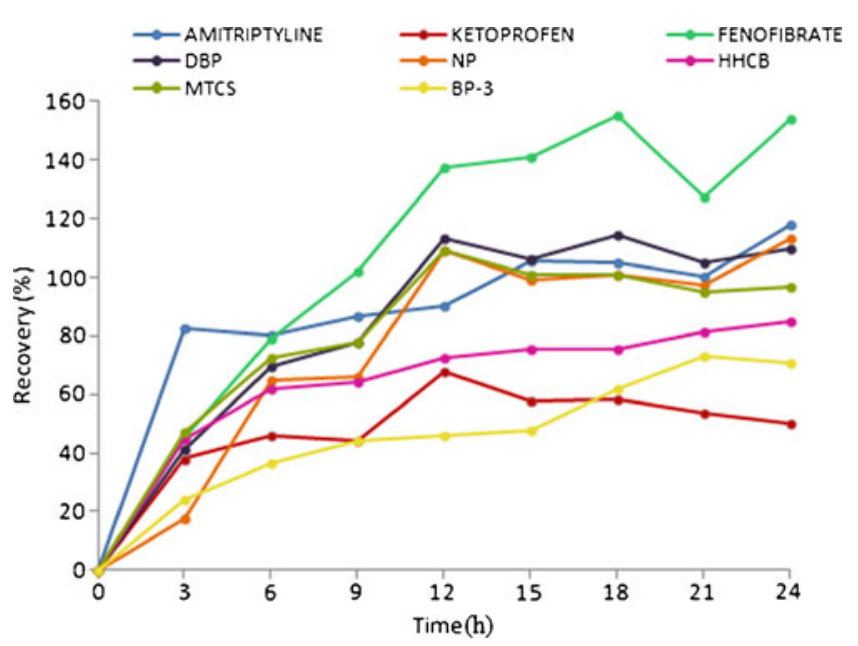

Fig. 1 SBSE efficiency (\%) versus extraction time (h) for selected analytes 
Addition of salts to the water samples was also tested, as this can improve the extraction efficiency for some compounds (salting-out effect), according to previous papers [3, $13,20]$. The effect of changes in the solution ionic strength on the recovery of analytes was studied by the addition of different amounts of sodium chloride $(0,100$, and $200 \mathrm{~g} / \mathrm{L})$. No clear trend was observed; results were significantly different from one compound to another (Fig. 2b). In general, addition of $\mathrm{NaCl}$ reduced the extraction of most of the apolar compounds (e.g., HHCB, OC, NP, and others having
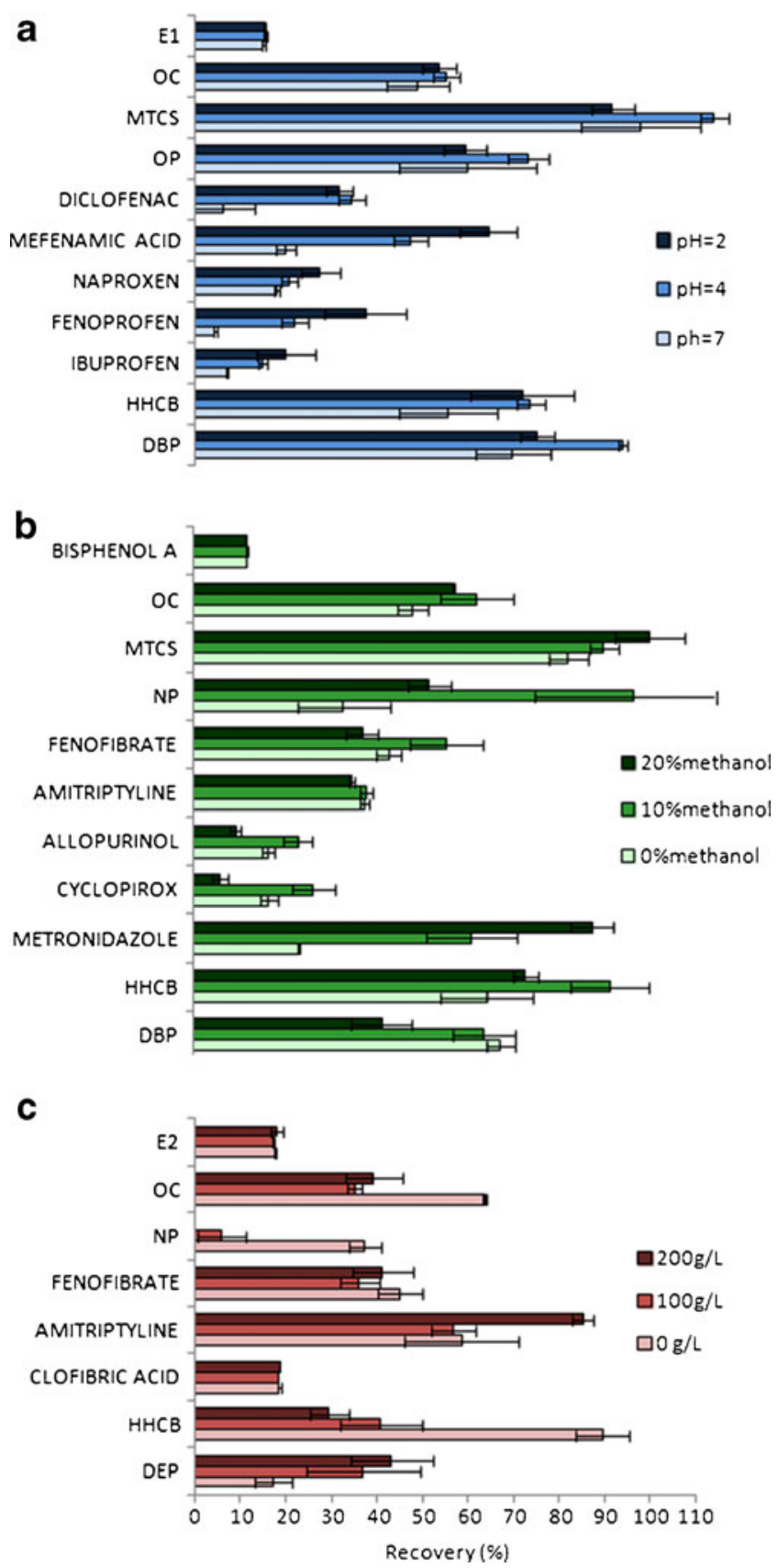

Fig. 2 Optimization of $\mathbf{a} \mathrm{pH}, \mathbf{b}$ organic modifier (\%), and $\mathbf{c}$ ionic strength for SBSE a $\log K_{\text {ow }}$ value higher than 5) by more than $30 \%$, which can presumably be attributed to enhanced sorption onto the glass walls [21, 24]. The opposite effect was observed for some of the more hydrophilic compounds (e.g., DEP and amitriptyline) but this benefit was not offset by large losses generated in other compounds. As a consequence, the best option for an optimal extraction of target compounds was not adding salt.

The last set of experiments was aimed at studying the effect of adding an organic modifier (methanol was selected) to the sample at different volumes $(0,10$, and $20 \%)$. This modifier could minimize the possible adsorption of some analytes onto the walls of glass, especially in the case of the most hydrophobic compounds [25]. As can be observed in Fig. 2c, extraction of weakly soluble chemicals (e.g., OP and $\mathrm{OC}$ ) was enhanced when a small amount of methanol (10 or $20 \%$ ) was added to the aqueous matrix. Higher percentages of methanol $(30 \%)$ were also tested (data not shown) but this proved to decrease dramatically $(>30 \%)$ the affinity for the PDMS bar of most compounds, except very hydrophobic fragrances. Extraction recovery percentages decreased progressively for most compounds within the medium to high polarity range (e.g., gemfibrozil, diclofenac, TCS, and DBP) as larger volumes of methanol were added to the samples [24]. Overall, and due to the combination of enhanced extraction of highly hydrophobic analytes from water samples and the need to add methanol to improve extraction of solid samples by PHWE (see below), $10 \%$ methanol was selected [26].

\section{$L D$ conditions}

The efficiency of liquid desorption after SBSE was tested by carrying out several experiments using different PDMS bar sizes (10 and $20 \mathrm{~mm}$ length), desorption solvents (methanol, acetonitrile, and ethyl acetate), and desorption times (from 10 to $60 \mathrm{~min}$ ). The rest of the parameters were fixed as follows: extraction time, $9 \mathrm{~h}$; agitation speed, $900 \mathrm{rpm}$; and sample volume, $10 \mathrm{~mL}$ (Milli-Q water spiked at $10 \mu \mathrm{g} / \mathrm{L}$ with target compounds).

After testing both bar sizes, we observed that differences in the SBSE efficiency were minimal (below $10 \%$ for most chemicals). However, selecting shorter stir bars $(10 \mathrm{~mm}$ length, $24 \mu \mathrm{L}$ of PDMS) proved to be crucial during $\mathrm{LD}$ as they required lower desorption solvent volumes than longer bars [27]. Thus, only $200 \mu \mathrm{L}$ per sample were sufficient for performing liquid desorption, which avoids the need for subsequent evaporation steps, possible analyte losses during this process, and final sample reconstitution in organic solvent.

Selection of organic solvents for the desorption step was limited to methanol, acetonitrile, and ethyl acetate because these are best suited for LD of volatile and semi-volatile 
compounds, according to previous studies [3, 27]. Differences in desorption efficiencies when using one or other of these solvents were minimal (less than $10 \%$ for any target compound); at the end ethyl acetate was selected because it is a solvent more suitable for GC analysis.

Liquid desorption of the target compounds was carried out by sonication, to accelerate the process. Several desorption times were tested $(10,30,40$, and $60 \mathrm{~min})$. For some analytes (e.g., TCS, fenoprofen, ketoprofen, or amitriptyline) there is an increase in desorption efficiencies of more than $20 \%$ when the desorption time is increased from $10 \mathrm{~min}$ to 30 or $40 \mathrm{~min}$. For most compounds, minimal differences (less than $5 \%$ ) were observed after applying sonication for 30,40 , or $60 \mathrm{~min}$. So $30 \mathrm{~min}$ was selected as an acceptable desorption time.

SBSE-LD recoveries for all target compounds using optimized conditions (extraction time $=8 \mathrm{~h}, \mathrm{pH}=2$, no salt addition, $10 \%$ of methanol as organic modifier, $10 \mathrm{~mm}$ length bars, desorption time $=30 \mathrm{~min}$, ethyl acetate as desorption solvent) are shown in Table 1.

\section{PHWE optimization}

Several experiments were performed in triplicate to evaluate the effect of the dispersing agent, extraction temperature, and percentage of methanol as organic modifier, for pressurized hot water extraction of target compounds. Preconcentration and clean-up of the resulting extract was carried out by SBSE-LD, which had previously been optimized (see above). Pressurized liquid extraction, which includes PHWE, needs the use of an inert dispersing agent in order to homogenize the samples and to fill the extraction cells $(22 \mathrm{~mL}$ ), thus minimizing the amount of solvent used during the extraction process. The most commonly used agents for extraction of organic compounds are quartz sand, siliceous earth, and sodium sulfate $[4,14]$. Siliceous earth was selected as a dispersing material in the experiments.

The conditions fixed for the rest of the experiments were three extraction cycles of $5 \mathrm{~min}$ each (enough for an optimal extraction according to previous works $[19,28]$ ), pressure of $1,500 \mathrm{psi}$ [28], and $2 \mathrm{~g}$ of sample. Temperature was optimized first as it is one of the most critical parameters affecting PHWE efficiency. Increasing temperature modifies the physico-chemical properties of water, decreasing its viscosity and surface tension. Polar compounds, such as pharmaceuticals, are generally better extracted at lower temperatures than non-polar compounds. Three extraction temperatures were tested: 50,100 , and $150{ }^{\circ} \mathrm{C}$. Higher temperatures were not tested because they could produce the degradation [15] or volatilization [29] of some PPCPs. Additionally, some authors have reported that higher temperatures also increase the co-extraction of matrix interferences that can make difficult subsequent analysis [29]. The results showed that extraction recoveries for a large number of compounds increased when temperature was raised from 50 to $100{ }^{\circ} \mathrm{C}$ (Fig. 3a). This increase was critical for some pharmaceuticals (e.g., acetaminophen, metronidazole, or allopurinol) that were not extracted at all at $50{ }^{\circ} \mathrm{C}$ but were at $100^{\circ} \mathrm{C}$. Slightly higher recovery percentages were observed for some compounds (fenofibrate and $\mathrm{OC}$ ) using higher temperatures $\left(150{ }^{\circ} \mathrm{C}\right)$ but they were offset by a decrease in the extraction efficiency of many others (several plasticizers, fragrances...). Therefore, $100{ }^{\circ} \mathrm{C}$ was selected as optimal extraction temperature; further, this value has previously been used to extract other contaminants such as surfactants [28] and persistent organic pollutants [4].

PHWE efficiency was then improved further by addition of an organic modifier to the extracting water that enhances the solubility of analytes. The amount of organic modifier was optimized by adding several volumes of methanol $(0$, 10 , and $20 \%$ ) to the water used for the extraction. We have observed that, although using pure water seemed to be adequate for extracting a significant number of the compounds (e.g., gemfibrozil, ketoprofen, amitriptyline...), the addition of methanol was mandatory for extracting some of the others, such as nonylphenol (Fig. 3b). As expected, the extraction efficiency of most of the apolar compounds (log $K_{\text {ow }}>5$ ), such as OC, NP, and HHCB, was improved by adding the higher percentage of methanol. Overall, better recoveries were observed for most analytes when organic modifier was added to water, although big differences were not found in the extraction efficiency (less than $15 \%$ ) between the addition of 10 or $20 \%$ of methanol. Considering these findings, and also that SBSE-LD has to be performed after PHWE and that the extraction efficiency of PDMS bars decreases for some target compounds as the methanol percentage increases (Fig. 2b) [18], adding $10 \%$ methanol was selected as a compromise. PHWE recoveries for all target compounds using optimized conditions $\left(100^{\circ} \mathrm{C}\right.$ and $10 \%$ of methanol as organic modifier) are shown in Table 1.

\section{Determination by GC-MS}

Separation, identification, and quantification of analytes were performed using gas chromatography-mass spectrometry. Derivatization was necessary for many of the target compounds either for transforming them into volatile compounds (e.g., ketoprofen) or for improving their chromatographic separation (e.g., TCS). Two derivatization agents were tested, MTBSTFA and acetic anhydride. The first agent produces a silylation reaction that generates tertbutyldimethylsilyl derivates (TBDMS), while acetic anhydride promotes acetylation of analytes. Adding acetic anhydride as derivatization agent directly into the water samples was tested and this improved the recovery of some 
Table 1 Target compounds, corresponding octanol-water partitioning coefficient $\left(K_{\text {ow }}\right)$, retention time (RT), ion selected for quantification $(Q 1)$ and qualitation $(Q 2)$, limits of detection in water and sediment
(LOD), calibration curves, coefficients of determination $\left(R^{2}\right)$, average recoveries, and relative standard deviation $(\% \pm \mathrm{RSD})$ of the analytical method

\begin{tabular}{|c|c|c|c|c|c|c|c|c|c|}
\hline Analyte & $\log K_{\mathrm{ow}}$ & RT (min) & $\left(Q 1, Q^{2}\right)$ & $\begin{array}{l}\text { LODs } \\
\text { in water } \\
(\mathrm{ng} / \mathrm{L})\end{array}$ & $\begin{array}{l}\text { LODs in } \\
\text { sediment } \\
(\mathrm{ng} / \mathrm{g})\end{array}$ & $\begin{array}{l}\text { Calibration } \\
\text { curve }\end{array}$ & $R^{2}$ & $\begin{array}{l}\text { Recovery } \\
\text { in water } \\
(\% \pm \mathrm{RSD})\end{array}$ & $\begin{array}{l}\text { Recovery } \\
\text { in sedimen } \\
(\% \pm \mathrm{RSD})\end{array}$ \\
\hline \multicolumn{10}{|l|}{ Repellent } \\
\hline DEET & 2.18 & 6.05 & 119,190 & 74 & 2 & $y=0.1953 x+0.0003$ & 0.9929 & $12.5 \pm 0.38$ & $5 \pm 0.6$ \\
\hline \multicolumn{10}{|l|}{ Plasticizers } \\
\hline DEP & 2.4 & 6.12 & 149,177 & 6 & 0.5 & $y=0.1043 x-0.0113$ & 0.9922 & $10.2 \pm 0.57$ & $26.7 \pm 0.3$ \\
\hline DBP & 4.6 & 9.89 & 149,150 & 2 & 0.04 & $y=0.0564 x-0.0049$ & 0.9943 & $61.1 \pm 6$ & $140 \pm 15$ \\
\hline \multicolumn{10}{|l|}{ Pharmaceuticals } \\
\hline Clofibric acid & 2.6 & 8.02 & 143,271 & 222 & 0.1 & $y=0.1889 x-0.0065$ & 0.9904 & $18.5 \pm 0.08$ & $8.67 \pm 0.17$ \\
\hline Ibuprofen & 3.97 & 8.5 & 263,264 & 11 & 0.1 & $y=0.0671 x+0.006$ & 0.9986 & $10 \pm 0.5$ & $5 \pm 0.1$ \\
\hline Metronidazole & & 9.41 & 143,227 & 22 & 0.8 & $y=7.5406 x-0.072$ & 0.9935 & $58.5 \pm 9$ & $49.2 \pm 0.15$ \\
\hline Cyclopirox & & 9.84 & 264,265 & 23 & 0.4 & $y=0.5906 x-0.0029$ & 0.9965 & $25.2 \pm 4$ & - \\
\hline Acetaminophen & 0.46 & 10.46 & 265,208 & 55 & 4 & $y=0.3302 x+0.0217$ & 0.994 & $12.7 \pm 0.3$ & $6.5 \pm 8$ \\
\hline Allopurinol & & 11.17 & 235,193 & 468 & 1 & $y=1.0778 x-0.0008$ & 0.9996 & $22 \pm 3$ & $6.75 \pm 0.93$ \\
\hline Gemfibrozil & 4.8 & 13.08 & 243,307 & 13 & 0.1 & $y=0.3589 x+0.0083$ & 0.9975 & $21.6 \pm 1.3$ & $25.4 \pm 1.8$ \\
\hline Amitriptyline & & 13.92 & 202,58 & 31 & 5 & $y=0.3555 x+0.033$ & 0.9961 & $36.5 \pm 1.4$ & $39.3 \pm 0.12$ \\
\hline Naproxen & 3.2 & 15.12 & 287,185 & 34 & 0.03 & $y=0.1693 x+0.0028$ & 0.9967 & $15.5 \pm 0.15$ & $31 \pm 0.7$ \\
\hline Fenoprofen & & 13.72 & 299,197 & 36 & 0.1 & $y=0.3664 x-0.0078$ & 0.998 & $10 \pm 1.9$ & $11.2 \pm 0.05$ \\
\hline Ketoprofen & 3.12 & 15.84 & 295,311 & 10 & 0.1 & $y=4.681 x-0.0218$ & 0.9976 & $21.2 \pm 1.7$ & $41 \pm 0.6$ \\
\hline Mefenamic acid & 5.12 & 17.36 & 224,298 & 1 & 0.03 & $y=0.1405 x+0.0072$ & 0.9932 & $29 \pm 2.2$ & $28 \pm 2.6$ \\
\hline Diclofenac & 4.51 & 19.02 & 352,354 & 37 & 0.7 & $y=2.261 x+0.0219$ & 0.9914 & $21 \pm 0.6$ & $11.3 \pm 0.2$ \\
\hline Fenofibrate & & 19.16 & 121,273 & 25 & 0.1 & $y=1.6062 x+0.0088$ & 0.9958 & $53.5 \pm 7.6$ & $50 \pm 5$ \\
\hline Carbamazepine & 2.47 & 18.29 & 193,293 & 146 & 0.5 & $y=0.2545 x-0.0137$ & 0.9919 & $2 \pm 0.08$ & $5.3 \pm 0.07$ \\
\hline \multicolumn{10}{|l|}{ Fragrances } \\
\hline НHCB & 5.9 & 8.67 & 243,213 & 0.9 & 0.03 & $y=0.2131 x+0.0033$ & 0.9973 & $87.7 \pm 8$ & $65 \pm 4.3$ \\
\hline MX & 4.8 & 8.78 & 282,283 & 1 & 0.6 & $y=0.6259 x-0.0013$ & 0.9967 & $39.2 \pm 2$ & $80 \pm 3$ \\
\hline \multicolumn{10}{|l|}{ Antibacterials } \\
\hline TCS & 4.8 & 16.06 & 347,345 & 0.2 & 0.03 & $y=0.2537 x-0.0162$ & 0.9979 & $23.8 \pm 1.6$ & $62 \pm 7$ \\
\hline MTCS (metabolite) & 5.2 & 12.34 & 302,304 & 0.8 & 0.01 & $y=0.1776 x-0.0068$ & 0.9915 & $86.4 \pm 3$ & $170 \pm 12$ \\
\hline \multicolumn{10}{|l|}{ UV filters } \\
\hline BP-3 & 3.79 & 15.2 & 285,286 & 2 & 0.07 & $y=0.1726 x+0.0111$ & 0.9971 & $27.6 \pm 1.3$ & $13.5 \pm 0.5$ \\
\hline $\mathrm{OC}$ & 6.88 & 20.86 & 232,248 & 0.6 & 0.3 & $y=2.7277 x-0.0176$ & 0.9981 & $59.6 \pm 7.8$ & $22.4 \pm 2$ \\
\hline \multicolumn{10}{|c|}{ Endocrine disruptor compounds (EDCs) } \\
\hline $\mathrm{OP}$ & 5.5 & 11.31 & 263,107 & 2 & 0.02 & $y=0.2055 x+0.0049$ & 0.9975 & $83.5 \pm 12.2$ & $9 \pm 1.4$ \\
\hline NP & 6 & $10.30-10.60$ & 235,277 & 11 & 0.2 & $y=2.0944 x-0.0182$ & 0.9929 & $92.2 \pm 20$ & $40 \pm 13$ \\
\hline Bp A & 3.5 & 21.55 & 441,207 & 4 & 0.2 & $y=0.0547 x-0.0118$ & 0.9927 & $11.15 \pm 0.08$ & $2.2 \pm 0.5$ \\
\hline E1 & 3.69 & 24.63 & 327,384 & 789 & 1 & $y=0.0869 x+0.0066$ & 0.9967 & $12.7 \pm 0.05$ & $3 \pm 0.003$ \\
\hline E2 & 4.13 & $<\mathrm{LOD}$ & 329,386 & 853 & - & $y=0.9594 x-0.0027$ & 0.9939 & $7 \pm 0.36$ & - \\
\hline $\mathrm{EE}$ & 4.25 & 25.92 & 410,353 & 508 & - & $y=0.187 x+0.0037$ & 0.9873 & $9 \pm 0.15$ & - \\
\hline
\end{tabular}

compounds such as UV filters [30]. However, we could also observe that this agent did not react with acidic pharmaceuticals, whereas MTBSTFA did when it was directly added into the vial after LD. Therefore, we chose adding $10 \mu \mathrm{L}$ of MTBSTFA to each sample after SBSE-LD. The reaction can take place at room temperature and, once formed, TBDMS compounds remain stable for several days [3].
Analytes were then separated along the GC column within 40 min (Fig. 4). Their identification in samples was based on comparing their retention times with those obtained for pure standards and by monitoring two selected ions per compound under SIM mode (Table 1). Calibration curves for water samples were constructed for each analyte by spiking Milli-Q water at different concentration levels 
Fig. 3 Optimization of a extraction temperature and $\mathbf{b}$ organic modifier (\%) for PHWE a

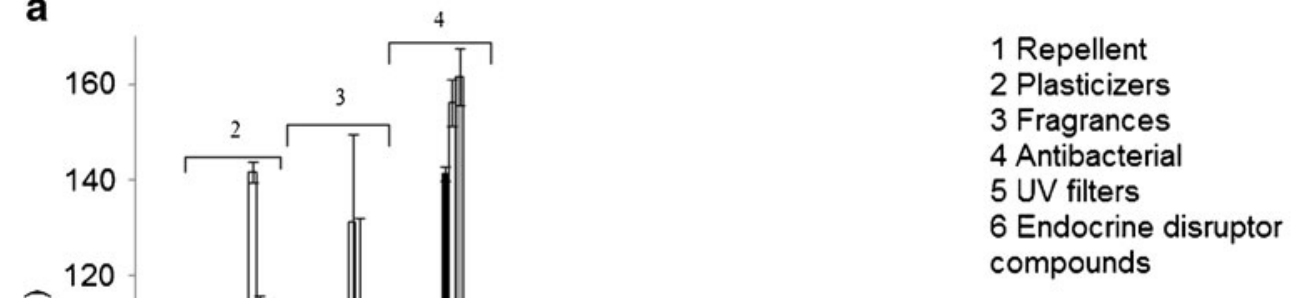

- $50^{\circ} \mathrm{C}$

- $100^{\circ} \mathrm{C}$

- $150^{\circ} \mathrm{C}$

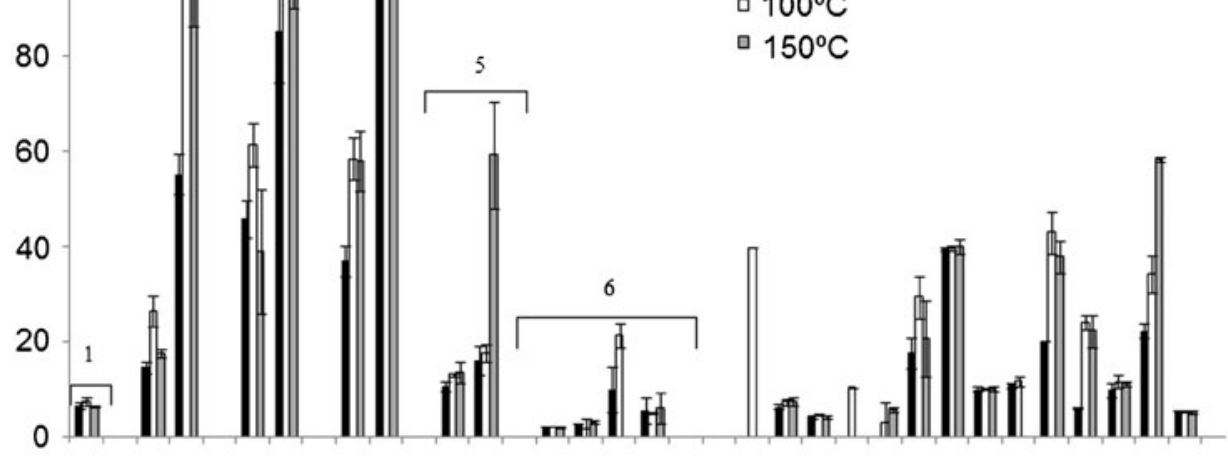

b

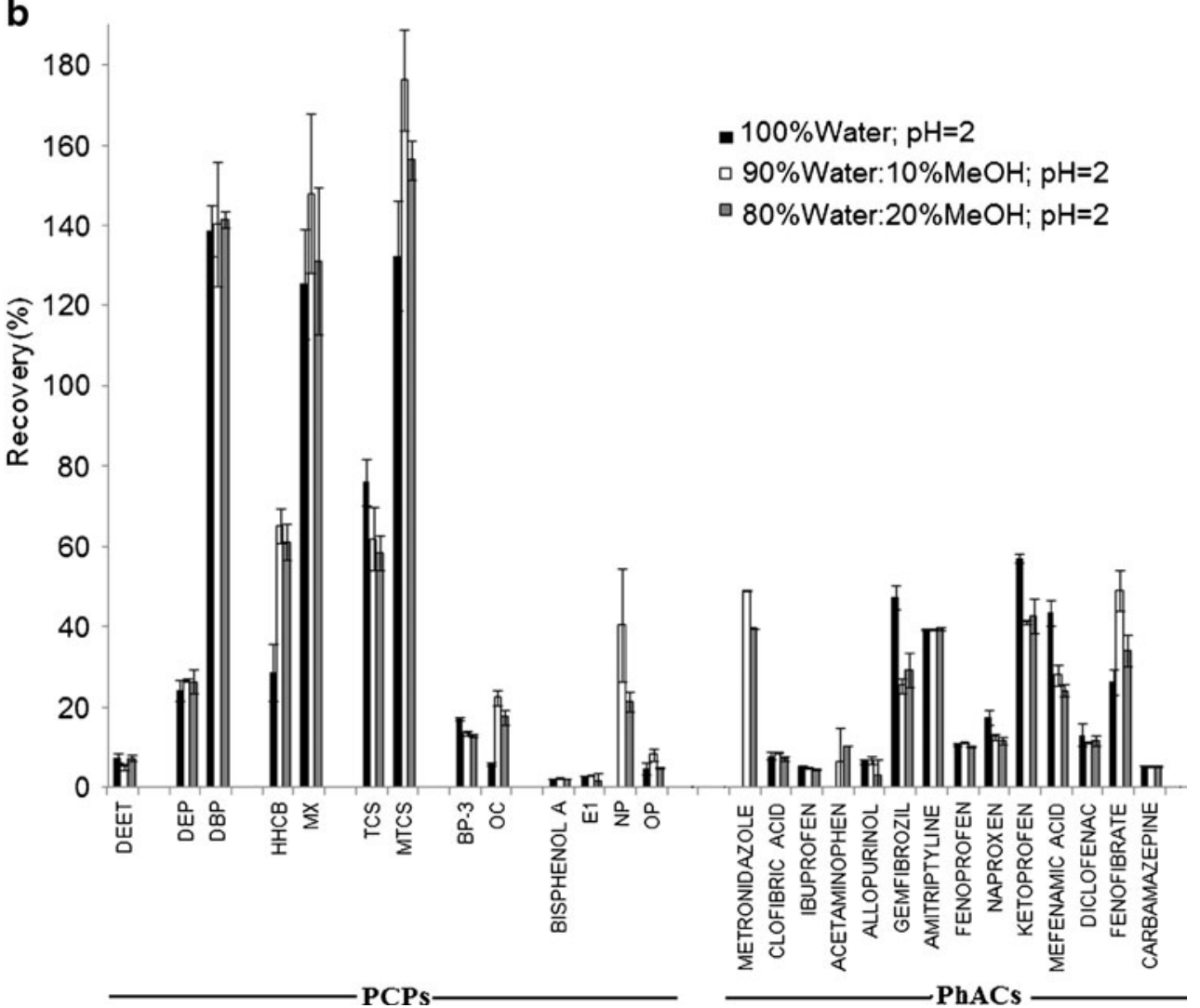

(0.01-10 $\mu \mathrm{g} / \mathrm{L})$ and extracting the analytes using PDMS bars. External calibration curves for solid samples were constructed by preparing different concentrations of target compounds $(1-100 \mu \mathrm{g} / \mathrm{kg})$ in vials. The behavior of all compounds was linear and coefficients of determination $\left(R^{2}\right)$ were above 0.99 . Concentrations were determined by measuring the peak area of one selected ion (quantitative ion, $Q 1)$ and were confirmed/validated using a second qualitative ion (Q2). Surrogates (MTCS-13C 12 and NP-d8) and internal standards (BpA-d14 and TCS-d3) were added at concentrations of 5 and $250 \mu \mathrm{g} / \mathrm{L}$, respectively, for all samples and calibration curves. The influence of matrix 
Fig. 4 EI+ GC-MS chromatogram from a standard showing the separation and identification of target compounds

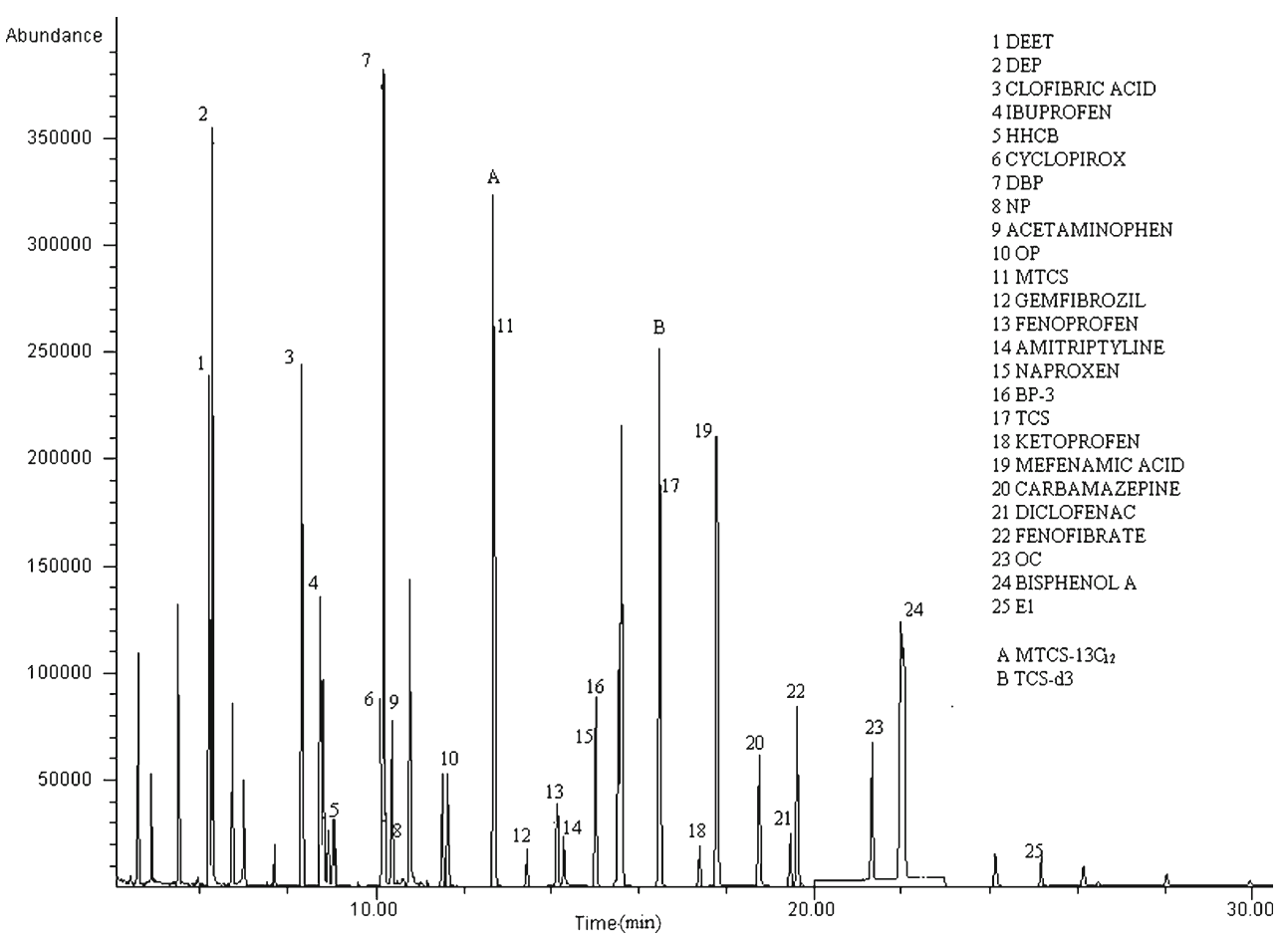

suppression was determined as a reduction of less than $15 \%$ of the signal intensity of internal standards for most samples, comparing with internal standard signal in the calibration curve. The repeatability of the method showed standard deviation values below $10 \%$ for all target compounds. Limits of detection were taken as the lowest concentration of the analytes in the calibration curve that could be detected, established for signal-to-noise ratios of 3 [31]. LOD values (Table 1) varied from 0.2 to $222 \mathrm{ng} / \mathrm{L}$ in water samples, except for estrones and allopurinol, whose limits were too high to carry out a reliable analysis of environmental samples. For sediment samples, LOD values were in the range between 0.02 and $5 \mu \mathrm{g} / \mathrm{kg}$, depending on the compound. These values are comparable with other previously reported $[3,19,26]$ and ensure the detection and quantification of most of the micro-contaminants, at environmental levels, considered in this work.

\section{Application to environmental samples}

Once the method was developed, it was applied to the analysis of target compounds in several matrices sampled from the Bay of Cadiz (SW of Spain): wastewater (influent and effluent), seawater, sediment, and pore water. These samples were analyzed in triplicate to determine the reproducibility of the method. Results are shown in Table 2. Standard deviation values were usually low (e.g., less than $13 \%$ in sediment samples, and less than $5 \%$ in pore water); thus the reproducibility of this method is considered adequate for the routine analysis of environmental samples. Overall, $56 \%$ of the analytes were detected.
For wastewater samples, the highest concentrations (ranging between 6.6 and $10.6 \mu \mathrm{g} / \mathrm{L}$ ) were found for ibuprofen, naproxen, and DEP in the influent, whereas other compounds were present at lower values (between $6 \mathrm{ng} / \mathrm{L}$ and $3.9 \mu \mathrm{g} / \mathrm{L}$, depending on the analyte considered) or they were not detected or quantified. As expected, most contaminants were detected at lower concentrations in the effluent than in the influent, usually below $1 \mu \mathrm{g} / \mathrm{L}$, except for naproxen, gemfibrozil, DEP, and HHCB. These values are of the same order of magnitude as those previously reported in other Spanish wastewater treatment plants [21,32].

Concentrations were even lower when comparing values found in seawater with those in the effluent. Thus, there is a significant reduction in the levels of most compounds between their reception in the treatment plant and their release into the ocean on discharge. Removal efficiencies of the WWTP, however, vary considerably depending on the analyte, ranging from 97 to $23 \%$, for ibuprofen and TCS, respectively. In some cases removal is not observed at all (e.g., BpA) and, for some compounds, such as NP and OP, concentrations found in seawater are even higher than those measured in wastewater. This could be due to further degradation of the parent compound (alkylphenol polyethoxylates) in the environment or due to the existence of other contamination sources, such as nearby ship docks [33].

Relatively few studies have been made on the occurrence and distribution of microcontaminants in sediments and, particularly, pore water, compared with those analyzing surface water and wastewater. Given this, the concentration values shown in Table 1 for some of the target compounds represent information available for the first time. Three 
Table 2 Concentrations of target compounds in different environmental matrices: sediment (nanograms per gram) and pore water (micrograms per liter) at selected depths $(0,10$, and $20 \mathrm{~cm})$, wastewater (influent and effluent), and seawater (micrograms per liter)

\begin{tabular}{|c|c|c|c|c|c|c|c|c|c|}
\hline \multirow[b]{3}{*}{ Compound } & \multicolumn{6}{|c|}{ Water $(\mu \mathrm{g} / \mathrm{L} \pm \mathrm{RSD})$} & \multicolumn{3}{|c|}{ Sediment (ng/g \pm RSD) } \\
\hline & \multicolumn{2}{|l|}{ Wastewater } & \multirow[t]{2}{*}{ Seawater } & \multicolumn{3}{|l|}{ Pore water } & & & \\
\hline & Influent & Effluent & & $\mathrm{cm} 0$ & $\mathrm{~cm} 10$ & $\mathrm{~cm} 20$ & $\mathrm{~cm} 0$ & $\mathrm{~cm} 10$ & $\mathrm{~cm} 20$ \\
\hline DEET & n.d. & n.d. & n.d. & n.d. & n.d. & n.d. & n.d. & $8.7 \pm 0.4$ & n.d. \\
\hline DEP & $10.63 \pm 0.9$ & $1.6 \pm 0.1$ & $1.7 \pm 0.8$ & $9 \pm 5.6$ & $4 \pm 1.9$ & 10 & $41 \pm 4.26$ & $37 \pm 0.07$ & 33 \\
\hline Clofibric acid & n.d. & n.d. & n.d. & n.d. & n.d. & n.d. & n.d. & n.d. & n.d. \\
\hline Ibuprofen & $6.62 \pm 0$ & $0.15 \pm 0$ & $0.01 \pm 0.001$ & $0.6 \pm 0.003$ & $0.5 \pm 0.01$ & 0.5 & $100 \pm 1.3$ & $98 \pm 0.09$ & 99 \\
\hline HHCB & $2.1 \pm 0.5$ & $1.1 \pm 0.08$ & $0.23 \pm 0.1$ & $0.5 \pm 0.009$ & $0.5 \pm 0.06$ & 0.5 & $78 \pm 8.32$ & $91 \pm 2.56$ & 36 \\
\hline MX & n.d. & n.d. & n.d. & $0.3 \pm 0.05$ & $2.7 \pm 0.6$ & 0.4 & n.q. & n.q. & n.q. \\
\hline Metronidazole & n.q. & n.q. & n.q. & n.q. & n.q. & n.q. & $36 \pm 3.11$ & $54 \pm 6.77$ & 43 \\
\hline Ciclopirox & n.q. & n.d. & n.d. & n.d. & n.q. & n.q. & n.d. & n.d. & n.d. \\
\hline DBP & $1.4 \pm 0.06$ & $0.37 \pm 0.004$ & $0.65 \pm 0.01$ & $2.35 \pm 1.13$ & $2.6 \pm 0.9$ & 3 & $47 \pm 1.2$ & $34 \pm 2.74$ & 32 \\
\hline NP & $0.28 \pm 0.1$ & $0.21 \pm 0.09$ & $0.44 \pm 0.1$ & $0.9 \pm 0.3$ & $3.8 \pm 1.2$ & 3.5 & $3 \pm 0.02$ & $13 \pm 3.25$ & 112 \\
\hline Acetaminophen & n.q. & n.q. & n.q. & $0.85 \pm 0.5$ & $1.7 \pm 0.35$ & 1.7 & $100 \pm 0.38$ & $96 \pm 0.12$ & 111 \\
\hline Allopurinol & n.d. & n.d. & n.d. & n.d. & n.d. & n.d. & n.d. & n.d. & n.d. \\
\hline $\mathrm{OP}$ & $0.1 \pm 0.02$ & $0.06 \pm 0.009$ & $0.5 \pm 0.1$ & $0.2 \pm 0.1$ & $0.06 \pm 0.04$ & 0.15 & n.d. & n.d. & 7 \\
\hline Gemfibrozil & $3.9 \pm 0.2$ & $1.6 \pm 0.01$ & $0.1 \pm 0.1$ & n.d. & n.d. & n.d. & n.q. & n.d. & n.d. \\
\hline Amitriptyline & n.q. & n.q. & n.d. & n.q. & n.q. & n.q. & n.q. & n.d. & n.d. \\
\hline Naproxen & $8.6 \pm 1.2$ & $3.1 \pm 0.13$ & n.q. & n.q. & n.q. & n.q. & $15.8 \pm 8.7$ & $1.2 \pm 0.2$ & 0.6 \\
\hline BP-3 & $0.1 \pm 0.1$ & $0.2 \pm 0.01$ & $0.07 \pm 0.001$ & $0.07 \pm 0.01$ & $0.04 \pm 0.01$ & 0.10 & $47 \pm 13.1$ & $26 \pm 3.1$ & 38 \\
\hline TCS & $0.12 \pm 0.002$ & $0.09 \pm 0.002$ & $0.04 \pm 0.006$ & $0.18 \pm 0.03$ & $0.2 \pm 0.01$ & 0.22 & $14 \pm 0.24$ & $43 \pm 2.64$ & 12 \\
\hline MTCS & $0.006 \pm 0$ & $0.006 \pm 0$ & n.q. & n.q. & n.q. & n.q. & n.q. & n.q. & n.q. \\
\hline Fenoprofen & n.d. & n.d. & n.d. & n.d. & n.d. & n.d. & $26 \pm 1.1$ & n.q. & n.d. \\
\hline Ketoprofen & $0.46 \pm 0.005$ & $0.1 \pm 0.003$ & n.q. & $0.2 \pm 0.03$ & n.d. & n.d. & n.d. & n.d. & n.d. \\
\hline Mefenamic acid & n.d. & n.d. & n.d. & $0.04 \pm 0.03$ & n.q. & n.d. & $23 \pm 12$ & $6 \pm 0.1$ & n.q. \\
\hline Carbamazepine & n.q. & n.d. & n.d. & n.d. & n.d. & n.d. & $15 \pm 3.71$ & $9 \pm 0.15$ & n.d. \\
\hline Diclofenac & $1.2 \pm 0.3$ & $0.24 \pm 0.08$ & n.q. & n.q. & n.q. & n.q & $10 \pm 2.86$ & n.d. & n.q. \\
\hline Fenofibrate & $0.13 \pm 0.08$ & $0.09 \pm 0.01$ & n.q. & $0.1 \pm 0.08$ & $0.07 \pm 0.003$ & 0.2 & n.q. & 0.18 & 0.2 \\
\hline $\mathrm{OC}$ & $1.3 \pm 0.2$ & $0.2 \pm 0.06$ & $0.1 \pm 0.01$ & $0.2 \pm 0.1$ & $0.1 \pm 0.009$ & 0.4 & $53 \pm 7.2$ & $20 \pm 1.9$ & 41 \\
\hline Bisphenol A & $0.008 \pm 0.0004$ & $0.009 \pm 0.0004$ & $0.009 \pm 0.0002$ & n.q. & n.q. & 0.05 & $148 \pm 19$ & $78 \pm 0.75$ & 73 \\
\hline E1 & n.d. & n.d. & n.d. & n.d. & n.d. & n.d. & n.q. & n.d. & n.d. \\
\hline E2 & n.d. & n.d. & n.d. & n.d. & n.d. & n.d. & n.d. & n.d. & n.d. \\
\hline $\mathrm{EE}$ & n.d. & n.d. & n.d. & n.d. & n.d. & n.d. & n.d. & n.d. & n.d. \\
\hline
\end{tabular}

n.d. not detected, n.q. not quantified

different depths were selected in the sedimentary column $(0$, 10 , and $20 \mathrm{~cm}$ from the surface). Concentrations found in sediment samples were up to $100 \mu \mathrm{g} / \mathrm{kg}$ for ibuprofen and acetaminophen. These pharmaceuticals are among the most frequently used in Spain [34] as they can be administered without medical prescription. Vertical distributions throughout the sedimentary column vary from one analyte to another: in some cases (e.g., naproxen and mefenamic acid) concentrations are lower at greater depths, whereas the opposite trend can be observed for other compounds such as NP. On the other hand, some of them showed more or less constant profiles with depth (e.g., ibuprofen and acetaminophen). These trends may depend on a combination of factors such as the use/ consumption of these compounds, the improvements made in the treatment of sewage in the area, and their possible degradation or persistence in the environment [35]. In any case, concentrations of analytes in these sediments can be considered as low $(<100 \mathrm{ng} / \mathrm{g})$ when they are compared with those previously found in this area for more widely used compounds such as surfactants [28]. Regarding their concentration in pore water, values are much lower than in sediment, and their detection and/or quantification were not possible in many cases. The highest concentrations found were up to $10 \mu \mathrm{g} / \mathrm{L}$ for DEP and $3.5 \mu \mathrm{g} / \mathrm{L}$ for NP.

Further studies are now being undertaken to improve our knowledge on the distribution of these and many other 
microcontaminants in the marine environment, since the information available on this topic is scarce, especially on their distribution in pore water and sediments, which are the ultimate sink for many of these compounds [36].

\section{Conclusions}

The aim of this study was to develop, optimize, and validate a multi-residue method for the determination of various pharmaceuticals and personal care products (fragrances, UV filters, repellents, endocrine disruptors, phthalates...) in both aqueous and solid environmental matrices. PHWE and SBSE-LD have been combined to minimize the use of organic solvents, reduce sample preparation time, and limit the manipulation of samples required, thus minimizing the risk of external contamination. Limits of detection achieved were between 0.2 and $853 \mathrm{ng} / \mathrm{L}$ for water samples, and between 0.01 and $5 \mu \mathrm{g} / \mathrm{kg}$ for solid samples; reproducibility and repeatability were also satisfactory, standard deviation values were usually lower than $10 \%$, thus ensuring that most of the target compounds can be reliably determined at trace levels. From the results obtained, the combination of PHWE and SBSE can be considered a reliable and more environmentally friendly alternative to more traditional (e.g., Soxhlet extraction) and widely used (e.g., solidphase extraction) techniques for extraction of a wide range of chemicals in environmental samples. In addition, liquid desorption could be a good solution to use the SBSE technique even when a thermal desorption unit is not available. One drawback encountered is, however, that extraction efficiencies were not high enough for the most polar compounds using existing commercially available PDMS bars, an issue that could be resolved by developing new polymers such as those already used in solid-phase microextraction. Finally, the method was successfully applied to the analysis of target compounds in selected real matrices - wastewater, seawater, marine sediment, and pore water. DEP, acetaminophen, ibuprofen, HCCB, NP, and OP were among the compounds most frequently detected.

Acknowledgments This study has been supported under two regional research projects (RNM 5417 and RNM 6613) and a FPI fellowship funded by the "Consejería de Economía, Innovación y Ciencia" of the Regional Government of Andalusia.

\section{References}

1. Network of reference laboratories for monitoring of emerging environmental pollutants /http://www.norman-network.net/index 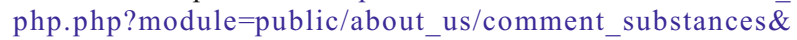 menu2=public $/$.
2. Bisceglia KJ, Yu JT, Coelhan M, Bouwer EJ, Roberts AL (2010) J Chromatogr A 1217:558-564

3. Quintana JB, Rodil R, Muniategui-Lorenzo S, López-Mahía P, Prada-Rodríguez D (2007) J Chromatogr A 1174:27-39

4. Durán-Alvarez JC, Becerril-Bravo E, Castro VS, Jiménez B, Gibson R (2009) Talanta 78:1159-1166

5. Azzouz A, Souhail B, Ballesteros E (2010) J Chromatogr A 1217:2956-2963

6. Xu J, Wu L, Chen W, Chang AC (2008) J Chromatogr A 1202:189-195

7. Pomati F, Castiglioni S, Zuccato E, Fanelli R, Vigetti D, Rossetti C, Calamari D (2006) Environ Sci Technol 40:2442-2447

8. Peck A (2006) Anal Bioanal Chem 386:907-939

9. Cottell A, Denyer SP, Hanlon GW, Ochs D, Maillard JY (2009) J Hosp Infect 72:71-76

10. Kuster M, López de Alda MJ, Barceló D (2004) TrAC-Trends Anal Chem 23:790-798

11. Winkler M, Headley JV, Peru KM (2000) J Chromatogr A 903:203-210

12. Baltussen E, Sandra P, David F, Cramer C (1999) J Microcol Sep 11:737-747

13. Pérez-Carrera E, León VM, Gómez-Parra A, González-Mazo E (2007) J Chromatogr A 1170:82-90

14. Lara-Martín PA, Gómez-Parra A, González-Mazo E (2006) J Chromatogr A 1114:205-210

15. Göbel A, Thomsen A, McArdell CS, Alder AC, Giger W, Theib N, Löffler D, Ternes TA (2005) J ChromatogrA 1085:179-189

16. Rice SL, Mitra S (2007) Anal Chim Acta 589:125-132

17. Hawthorne SB, Yang Y, Miller DJ (1994) Anal Chem 66:2912-2920

18. Concha-Graña E, Fernández-González V, Grueiro-Noche G, Muniategui-Lorenzo S, López-Mahía P, Fernández-Fernández E, Prada-Rodríguez D (2010) Chemosphere 79:698-705

19. Saleh A, Larsson E, Yamini Y, Jönsson JA (2011) J Chromatogr A 1218:1331-1339

20. Camino-Sánchez FJ, Zafra-Gómez A, Pérez-Trujillo JP, CondeGonzález JE, Marques JC, Vílchez JC (2011) Chemosphere 84:869-881

21. Ramírez N, Marcé RM, Borrull F (2011) J Chromatogr A 1218:156-161

22. Liu WM, Hu Y, Zhao JH, Xu Y, Guan YF (2005) J Chromatogr A 1095:1-7

23. http://www.drugbank.ca/

24. León VM, Álvarez B, Cobollo MA, Muñoz S, Valor I (2003) J Chromatogr A 999:91-101

25. Gomez MJ, Herrera S, Sole D, Garcia-Calvo E, Fernandez-Alba AR (2011) Anal Chem 83:2638-2647

26. Rodil R, Moeder M (2008) J Chromatogr A 1179:81-88

27. Silva ARM, Nogueira JMF (2010) Anal Bioanal Chem 396:18531862

28. Lara-Martín PA, Petrovic M, Gómez-Parra A, Barceló D, González-Mazo E (2006) Environ Pollut 144:483-491

29. Petrovic M, Lacorte S, Viana P, Barceló D (2002) J Chromatogr A 959:15-23

30. Kawaguchi M, Ito R, Honda H, Endo N, Okanouchi N, Saito K, Seto Y, Nakazawa H (2008) J Chromatogr A 1200:260-263

31. Shrivastava A, Gupta VB (2011) Chron Young Sci 2:21-25

32. Valcarcel Y, Alonso SG, Rodriguez-Gil JL, Maroto RR, Gil A, Catalá M (2011) Chemosphere 82:1062-1071

33. Jonkers N, Laane RW, de Voogt P (2002) Environ Sci Technol $37: 321-327$

34. International Marketing Service, Pharmaceutical Market, Supplement generic pharmaceuticals (2010, December).

35. Kupper T, Plagellat C, Brändli RC, de Alencastro LF, Grandjean D, Tarradellas J (2006) Water Res 40:2603-2612

36. Cantwell MG, Wilson BA, Zhu J, Wallace GT, King JW, Olsen CR, Burgess RM, Smith JP (2010) Chemosphere 78:347-352 